\title{
FACTORS PREDICTING THE STRETCHING EXERCISE BEHAVIORS OF OFFICE EMPLOYEES WORKING IN THE SHAHID BEHESHTI UNIVERSITY OF MEDICAL SCIENCES IN TEHRAN, IRAN
}

\author{
Mohammad Hossein-Delshad ${ }^{1}$, Sedigheh Sadat-Tavafian ${ }^{1 *}$ and Anoshirvan Kazemnejad ${ }^{2}$ \\ Departments of ${ }^{1}$ Health Education and Health Promotion and ${ }^{2}$ Biostatistics, Faculty of Medical Sciences, \\ Tarbiat Modares University, Tehran, Iran.
}

\begin{abstract}
Background: Office employees of all ages are at risk for non-communicable diseases such as musculoskeletal disorders (MSDs) due to physical inactivity. Stretching exercise (SE) behavior could help office employees prevent MSDs. This research aimed to study the predictors of SE among office employees working in Shahid Beheshti University of Medical Sciences (SBUMS) of Iran through a health promotion model (HPM). Methods: In the present study, 430 eligible office employees were randomly selected. To assess the predictors of SE, all the HPM constructs were examined as risk factors to determine whether they influence the probability of SE behavior occurrence and were interpreted through odds ratio (OR). SPSS version 19 was used to analyze the data. Results: A total of 420 office employees with mean age of $37.1 \pm 8.03$ years took part in the study. This study showed that perceived barriers to action could prevent participants from engaging in SE (OR [95\% Cl]: 0.875 [0.815-0.939], $\mathrm{p}<0.001$ ). However, perceived self-efficacy (OR [95\% Cl]:1.248 [1.137-1.370], p < 0.001), commitment to a plan of action (OR [95\% Cl]: 1.189 [1.033-1.367], $p=0.016$ ), and interpersonal influences (OR [95\% Cl]: 1.104 [1.041-1.217], p = 0.003) were significant predictors for SE behavior. Conclusions: This study showed that the office employees who were more confident and committed to a plan of action, and perceived fewer barriers, were more likely to engage in SE behavior. (REV INVEST CLIN. 2019;71:178-85)
\end{abstract}

Key words: Health promotion model. Stretching exercise. Office employee.

Corresponding author:

* Sedigheh Sadat-Tavafian

Department of Health Education

and Health Promotion

Faculty of Medical Sciences

Tarbiat Modares University

Ghisa St., Jalae Ale Ahmd Ave. No 212

P.O. BOX: 14115-111, Tehran, Iran

Received for publication: 03-08-2018

E-mail: tavafian@modares.ac.ir

Approved for publication: 14-11-2018

DOI: $10.24875 / R I C .18002694$ 


\section{INTRODUCTION}

Globally, one-third of the general population suffers from some kind of chronic pain ${ }^{1}$, among which the most prevalent health problem is work-related musculoskeletal disorders (WRMSDs), with severe longterm pain and physical disability². Clinical practice guidelines, such as those of the International Association for the Study of Pain ${ }^{3}$, recommend that physical activity be an integral component of pain rehabilitation services. Although exercise programs have been shown to benefit individuals with chronic pain ${ }^{4,5}$, physical inactivity is one of the most crucial factors for WRMSDs worldwide ${ }^{6}$. In Iran, insufficient physical activity has been reported in $33.5 \%$ of adults, increasing in recent years ${ }^{7}$. The World Health Organization has predicted that physical inactivity will reduce by up to $10 \%$ by $2025^{8}$. Stretching exercise (SE) is a kind of physical exercise in which a specific muscle is flexed or stretched to achieve better muscle tone as well as improved muscle control, flexibility, and motion'. The previous studies have shown that performing SE could help individuals' muscles to stretch and flex better and, finally, could improve musculoskeletal disorders (MSDs) ${ }^{10}$.

The office employees in Iranian universities sit at their desk during working hours without engaging in $\mathrm{SE}^{11}$. Despite the mentioned benefits of $\mathrm{SE}^{11}$, issues related to a lack of adherence to this activity or motivational factors are poorly understood ${ }^{1}$. Therefore, to predict and explain the factors influencing SE behavior is crucial to many researchers and professionals who are engaged in designing proper interventions to improve and promote this beneficial activity among office employees ${ }^{12}$.

Health promotion model (HPM) is one of the comprehensive models by which the factors influencing an individual to follow healthy behaviors could be predicted through its eight constructs, shown in figure $1^{13}$. Pender et al. believed that worksite health promotion programs could help employees to develop healthy behaviors that could lead to lower health-care costs and enhanced productivity. However, before designing the programs based on the HPM, the efficacy of this model on SE behavior and predicted effective factors should be considered. In this regard, the present study aimed to assess whether HPM constructs predict SE behavior among office employees working in the Shahid Beheshti University of Medical Sciences (SBUMS) in Teheran, Iran.

\section{METHODS}

\section{Gemini study and participants}

This study was done among the office employees who were working in the three health networks of North, East, and Shemiranat region of Tehran and were affiliated to SBUMS in Tehran, Iran, from May to September 2017. All ethical issues were considered in this research. After explaining the aims and procedures of the study, all participants agreed to be studied and voluntarily signed the written consent form. The Research Ethics Committee of Tarbiat Modares University approved the study in May 2016 (ID 52/1115 IR.TMU.REC.1395.329).

In the present study, 430 eligible office employees were randomly selected. Figure 2 shows the procedure of participation sampling. Inclusion criteria were to be working in the SBUMS as an employee and working on the computer at the workplace. Exclusion criteria were to have any disability or illness that prevented the employee from doing SE or not being allowed to do SE due to his or her physician's recommendation. To assess the predictors of SE, all the HPM constructs (Fig. 1) were examined as risk factors, which could influence the probability of occurrence of $\mathrm{SE}$ and were interpreted through odds ratio (OR)14. Based on the existing reference, the sample size was estimated assuming five individuals for each item15. Therefore, for a 77-item questionnaire, a sample size of $77 \times 5=385$ was calculated.

\section{Study design}

In this cross-sectional study, a demographic questionnaire, self-administered questionnaires based on HPM, and checklists regarding SE behaviors were used. The questionnaire regarding HPM constructs was developed by the researchers based on the existing literature and interview with key persons. The HPM constructs questionnaire included eight subscales according to HPM constructs (Fig. 1). The questionnaire based on HPM constructs is shown in Supplementary Table 1; in addition, this figure shows the barriers which were perceived by the studied 
Figure 1. Schematic representation of health promotion model (HPM) (Pender, 2015 13 ).

The HPM framework is based on the HPM by which health behavior predicting factors have been shown.

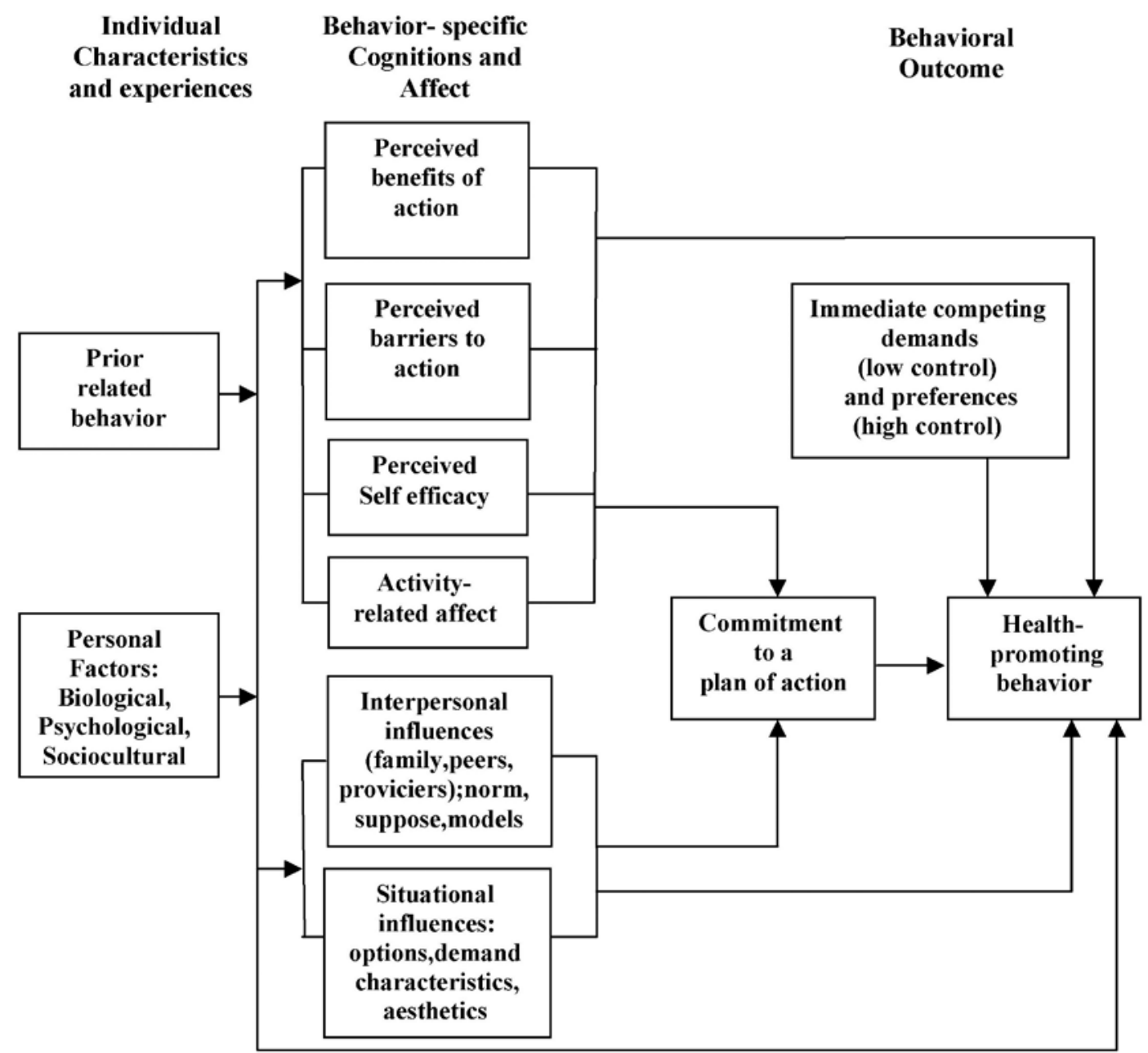

employees. The SE behavior checklist was assessed using a 10-item questionnaire. Participants also answered a two-option question about performing specific SE for stretching neck, shoulder, and back muscles.

Sufficient stretching was defined as a stretched position for each muscle for $10-30 \mathrm{~s}$ to be repeated 3 or 4 times every 20 min for 5 days a week ${ }^{16-19}$. Qualitative and quantitative approaches were applied by 15 office employees to assess facial validity of the HPM constructs questionnaire through which all their recommendations were inserted into the questionnaire. To confirm the content validity of the questionnaire, the expert panel, including 15 specialists in different fields of health education, psychology, psychometric, physical medicine, nursing, pain management, neurology, and orthopedics, checked all the survey items by which 9 of 86 questions did not obtain the minimum agreement of necessity and were omitted. Finally, 77 items were approved. The reliability was determined through Cranach's alpha coefficient that was in an acceptable range of 0.7-0.88.

\section{Statistical analyses}

To determine the relationship between different HPM constructs with each other and with SE behavior, $\mathrm{R}$ Spearman was used because the K-S test showed that the data were non-parametric. To predict the factors influencing SEs, logistic regression analysis was applied. In logistic regression, the regression coefficient (b1) is the estimated increase in the log odds of SE occurrence per unit increase in the value of the HPM 
Figure 2. Flow diagram of participation sampling among office employees working in three health networks of North, East, and Shemiranat region of Tehran, Iran.

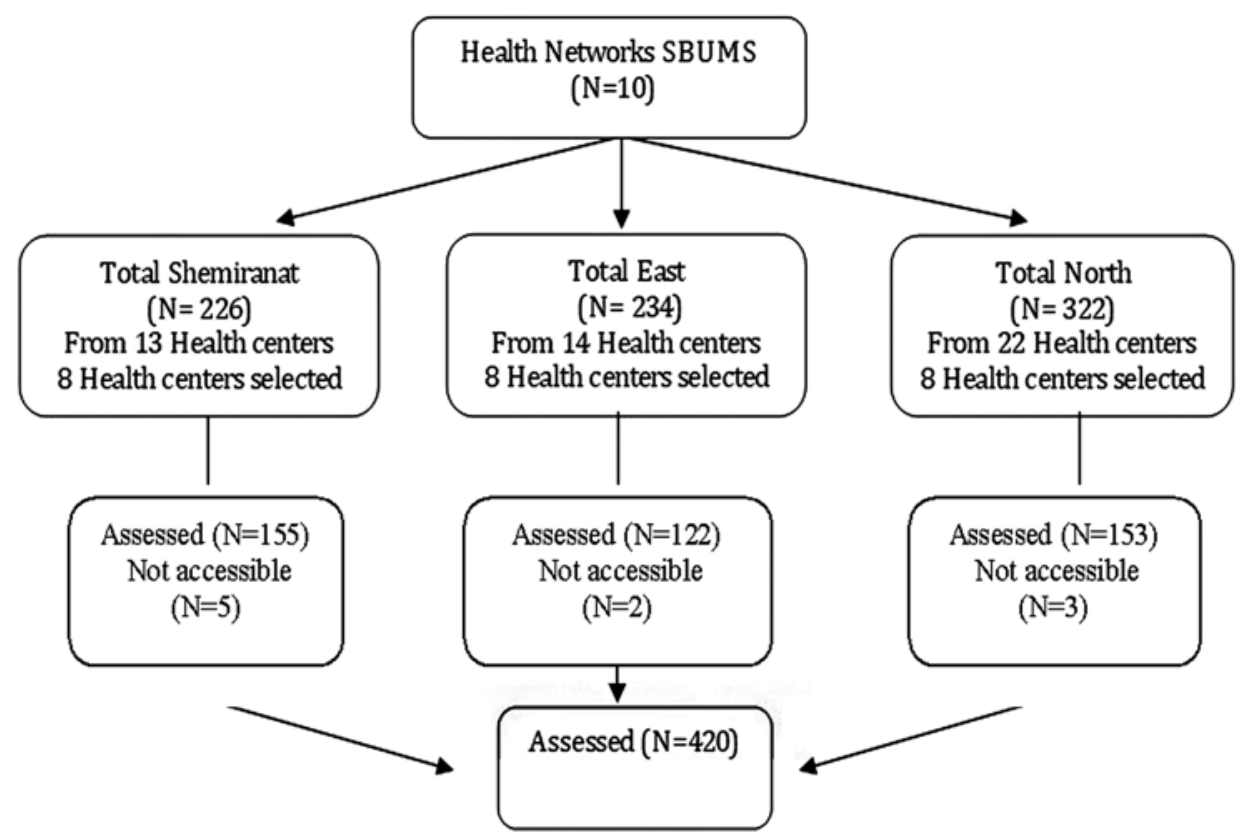

constructs. Moreover, in this study, the OR represents the odds of SE occurring given exposures such as HPM constructs, compared to the odds of SE occurring in the absence of HPM constructs. OR = 1 means that exposure does not affect odds of SE; OR > 1 means exposure associated with higher odds of SE; and OR $<1$ means exposure associated with lower odds of SE. $p<0.05$ was considered statistically significant.

\section{RESULTS}

\section{Sociodemographic variables}

Of a total of 430 office employees recruited, 420 took part in the study and filled the questionnaires (response rate $97.2 \%$ ). Mean age of participants was 37.1 years $(S D=8.03)$ and most of them $(25.2 \%)$ were between 30 and 34 years old. Overall, 154 employees (36.6\%) were suffering from MSDs. Table 1 shows sociodemographic data as well as the mean (SD) of all studied variables based on HPM.

Spearman's correlation tests were used to evaluate the relevance between the constructs of HPM with each other and with SE behavior (Table 2). As this table shows, there was a significant inverse correlation between SE and perceived barriers to action so that the office employees who perceived more barriers to action were significantly less likely to have SE behavior $(p<0.001)$.

As table 3 shows, perceived barriers to action were a negative predictor for engaging in SE (OR [95\% $\mathrm{Cl}]: 0.8755$ [0.8151-0.9391], $\mathrm{p}<0.001$ ). Furthermore, the results of this study showed that perceived self-efficacy (OR [95\% Cl]: 1.248 [1.137$1.370], p<0.001$ ), interpersonal influences (OR [95\% Cl]: 1.126 [1.041-1.217], $p=0.003$ ), and commitment to a plan of action (OR $[95 \% \mathrm{Cl}]$ : 1.118 [1.033-1.367], $p=0.016$ ) were positive predictors for the SE behavior.

\section{DISCUSSION}

To understand better why adult individuals do not engage in SE is important to professionals who develop behavior-changing interventions ${ }^{20}$. Our study was carried out to address this challenge through the identification of predicting factors for SE behavior among Iranian office employees of a large university center; according to our results, self-efficacy was the most important predictor. These results 
Table 1. Sociodemographic characteristics of the studied office employees

\begin{tabular}{|c|c|c|c|}
\hline Studied variables and constructs & Sufficient & n (\%) & Mean (SD) \\
\hline Age, years & $\begin{array}{l}21-24 \\
25-29 \\
30-34 \\
35-39 \\
40-44 \\
\geq 45\end{array}$ & $\begin{array}{c}26(6.2) \\
45(10.7) \\
106(25.2) \\
78(18.6) \\
97(23.1) \\
68(16.2)\end{array}$ & $37.1 \pm 8.03$ \\
\hline Years of education & $\begin{array}{c}12 \\
14 \\
16 \text { (Bachelor) } \\
18 \text { (Master) }\end{array}$ & $\begin{array}{c}45(10.7) \\
258(61.4) \\
60(14.3) \\
57(13.6)\end{array}$ & $4.3 \pm 0.8$ \\
\hline Work experience (years) & $\begin{array}{c}\leq 5 \\
5-10 \\
11-15 \\
16-20 \\
\geq 20\end{array}$ & $\begin{array}{c}157(37.4) \\
69(16.4) \\
71(16.9) \\
78(18.6) \\
45(10.7)\end{array}$ & $2.4 \pm 1.4$ \\
\hline Suffering from WRMSD pain & $\begin{array}{l}\text { Yes } \\
\text { No }\end{array}$ & $\begin{array}{l}154(36.6) \\
266(63.6)\end{array}$ & - \\
\hline Marital status & $\begin{array}{c}\text { Single } \\
\text { Married } \\
\text { Widowed } \\
\text { Divorced }\end{array}$ & $\begin{array}{c}120(28.6) \\
289(68.8) \\
5(1.2) \\
6(1.4)\end{array}$ & \\
\hline \multicolumn{3}{|l|}{ Perceived benefits of action } & $17.90 \pm 5.05$ \\
\hline \multicolumn{3}{|l|}{ Perceived barriers to action } & $20.85 \pm 6.03$ \\
\hline \multicolumn{3}{|l|}{ Perceived Self efficacy } & $17.15 \pm 3.71$ \\
\hline \multicolumn{3}{|l|}{ Activity-related affect } & $16.27 \pm 2.45$ \\
\hline \multicolumn{3}{|l|}{ Interpersonal influences } & $11.55 \pm 4.64$ \\
\hline \multicolumn{3}{|l|}{ Commitment to plan of action } & $16.82 \pm 4.28$ \\
\hline \multicolumn{3}{|c|}{ Immediate competing demands and preferences } & $11.70 \pm 2.80$ \\
\hline \multicolumn{3}{|l|}{ Situational influences } & $14.64 \pm 4.59$ \\
\hline Stretching exercise (TE) & $\begin{array}{l}\text { Yes } \\
\text { No }\end{array}$ & $\begin{array}{l}191(45.47) \\
229(54.53)\end{array}$ & - \\
\hline
\end{tabular}

Mean (SD): mean (Standard deviation)

agree with those from a previous study ${ }^{21}$, by which the motivational phase, the role of action planning, and self-efficacy were determined as influencing factors for SE behavior. Furthermore, the results of the present study are completely in the line of theoretical assumptions of the health action process approach ${ }^{20}$. Moreover, in accordance with our study, numerous studies have shown that perceived self-efficacy has been the best predictor variable for actual exercise activity 22-24. Therefore, strategies for enhancing efficacy in practice, such as strengthening self-efficacy through motivational counseling interviews and focus group discussions, could lead to more effective health promotion programs for Iranian office employees and should be considered in future interventions ${ }^{25}$. These programs could propose that highly self-efficacious individuals exerted greater efforts to master health-promoting behaviors and persist longer in the face of obstacles to such behaviors. Perceived self-efficacy acknowledges the human self-regulation capacity and competencies in specific behavioral domains such as SE. Perceived self-efficacy is not only among the skills one should acquire but is also a belief about what one can do under different situations ${ }^{26}$. Laffrey reported in his research that Bandura noted that the perception of selfefficacy influences one's thoughts, emotional arousal, and actions, and the higher one's perceived efficacy for a behavior is that it is more likely that she/he will accomplish such behavior ${ }^{23}$. In this study, the variables of perceived barriers that had a negative association were 
Table 2. Correlation matrix of the constructs of health promotion model in stretching exercise in office employees

\begin{tabular}{|c|c|c|c|c|c|c|c|c|c|}
\hline Variables & 1 & 2 & 3 & 4 & 5 & 6 & 7 & 8 & 9 \\
\hline $\begin{array}{l}\text { 1. Perceived benefits } \\
\text { of action }\end{array}$ & 1 & & & & & & & & \\
\hline $\begin{array}{l}\text { 2. Perceived barriers } \\
\text { to action }\end{array}$ & $\begin{array}{c}r= \\
-0.383^{* *}\end{array}$ & 1 & & & & & & & \\
\hline 3. Perceived self-efficacy & $\begin{array}{c}r= \\
0.423^{* *}\end{array}$ & $\begin{array}{c}r= \\
0.660^{* *}\end{array}$ & 1 & & & & & & \\
\hline $\begin{array}{l}\text { 4. Activity-related } \\
\text { affect }\end{array}$ & $\begin{array}{c}r= \\
0.371^{* *}\end{array}$ & $\begin{array}{l}r= \\
0.113\end{array}$ & $\begin{array}{c}r= \\
0.342^{* *}\end{array}$ & 1 & & & & & \\
\hline $\begin{array}{l}\text { 5. Interpersonal } \\
\text { influences }\end{array}$ & $\begin{array}{c}r= \\
0.453^{* *}\end{array}$ & $\begin{array}{c}r= \\
0.585^{* *}\end{array}$ & $\begin{array}{c}r= \\
0.583^{* *}\end{array}$ & $\begin{array}{c}r= \\
0.282^{* *}\end{array}$ & 1 & & & & \\
\hline $\begin{array}{l}\text { 6. Commitment } \\
\text { to plan of action }\end{array}$ & $\begin{array}{c}r= \\
0.730^{* *}\end{array}$ & $\begin{array}{c}r= \\
0.509^{* *}\end{array}$ & $\begin{array}{c}r= \\
0.709 * *\end{array}$ & $\begin{array}{c}r= \\
0.510^{* *}\end{array}$ & $\begin{array}{c}r= \\
0.627^{* *}\end{array}$ & 1 & & & \\
\hline $\begin{array}{l}\text { 7. Immediate competing } \\
\text { demands and } \\
\text { preferences }\end{array}$ & $\begin{array}{l}r= \\
0.050\end{array}$ & $\begin{array}{l}r= \\
0.040\end{array}$ & $\begin{array}{l}r= \\
0.003\end{array}$ & $\begin{array}{l}r= \\
0.021\end{array}$ & $\begin{array}{c}r= \\
0.130^{* *}\end{array}$ & $\begin{array}{l}r= \\
0.073\end{array}$ & 1 & & \\
\hline 8. Situational influences & $\begin{array}{c}r= \\
0.129^{* *}\end{array}$ & $\begin{array}{l}r= \\
0.008\end{array}$ & $\begin{array}{c}r= \\
0.98^{* *}\end{array}$ & $r=0.092^{* *}$ & $\begin{array}{c}r= \\
0.145^{* *}\end{array}$ & $\begin{array}{c}r= \\
0.197^{* *}\end{array}$ & $\begin{array}{l}r= \\
0.065\end{array}$ & 1 & \\
\hline 9. Stretching exercise & $\begin{array}{c}r= \\
0.327^{* *}\end{array}$ & $\begin{array}{c}r= \\
0.523^{* *}\end{array}$ & $\begin{array}{c}r= \\
0.581^{* *}\end{array}$ & $r=0.208^{* *}$ & $\begin{array}{c}r= \\
0.540^{* *}\end{array}$ & $\begin{array}{c}r= \\
0.558^{* *}\end{array}$ & $\begin{array}{l}r= \\
0.076\end{array}$ & $\begin{array}{c}r= \\
0.107^{*}\end{array}$ & 1 \\
\hline
\end{tabular}

**Spearman's correlation is meaningful at 0.01 levels (two-sided). *Correlation is meaningful at the 0.05 level (two-sided).

Table 3. Predictors of stretching exercise behavior based on health promotion model through logistic regression analysis

\begin{tabular}{|c|c|c|c|c|}
\hline Independent variable & B & SE & $\mathrm{p}$ & OR $(95 \% \mathrm{Cl})$ \\
\hline Perceived benefits of action & -0.031 & 0.043 & 0.471 & $0.970(0.892-1.054)$ \\
\hline Perceived barriers to action & -0.134 & 0.036 & $<0.001$ & $0.875(0.815-0.939)$ \\
\hline Perceived self-efficacy & 0.222 & 0.048 & $<0.001$ & $1.248(1.1371-1.370)$ \\
\hline Activity-related affect & -0.116 & 0.073 & 0.112 & $0.890(0.771-1.028)$ \\
\hline Interpersonal influences & 0.099 & 0.04 & 0.003 & $1.104(1.041-1.217)$ \\
\hline Commitment to plan of action & 0.173 & 0.072 & 0.016 & $1.189(1.033-1.367)$ \\
\hline $\begin{array}{l}\text { Immediate competing demands } \\
\text { and preferences }\end{array}$ & 0.017 & 0.053 & 0.741 & $1.018(0.918-1.129)$ \\
\hline Situational influences & -0.057 & 0.04 & 0.158 & $0.945(0.874-1.022)$ \\
\hline
\end{tabular}

demonstrated to be significant predictors for SE among office employees. This finding is supported by several previous studies, in which individuals who perceived more barriers to the performance of exercise were less likely to engage in this behavior ${ }^{24,27}$.

Pender et al. focused on a perceived barrier as an essential mediator of the motivational readiness of individuals to developing a healthy behavior ${ }^{13}$. In the present study, the barriers for engaging in SE were measured using a 9-item scale in which each item stated one barrier. Justine et al. stated that the perceived barriers to physical activity consisted of both internal factors such as individual sociodemographic features, health and motivation precedence for exercise and physical activity, as well as external factors such as the influence of peers and family, lack of time, inaccessibility, and high cost of facilities ${ }^{27}$. According to this finding, a problem-solving approach for overcoming barriers to physical activity should be considered in exercise intervention programs. To promote SE, it is necessary to solve the perceived barriers which were predictive. In other studies ${ }^{28,29}$, perceived barriers predicted physical activity behavior. 
The findings of this study showed the beneficial effects of commitment to a plan of action on SE. The previous evidence has revealed the relationship between action planning and maintaining self-efficacy, on the one hand, and exercise behavior on the other ${ }^{30}$. Experimental and field studies have supported the idea that action planning refers to designing detailed plans regarding when, where, and how to exercise, and predicts exercise beyond goal intention ${ }^{31}$.

In the current study, there was also a relationship between interpersonal influences and SE. Moreover, there was also a relationship between situational influences and commitment to a plan of action. Similar to the present study, commitment to a plan of action and perceived barriers to action were the most predictive factors of the exercise behavior. These results are consistent with previous studies 29,32 , which have shown that interpersonal influences are related to the studied behavior ${ }^{29}$.

The current study revealed that perceived self-efficacy, perceived barriers, and commitment to a plan of action as well as interpersonal influences among office employees should be given more attention for improving SE behavior. There are several limitations to this study. First, the data used were gathered through selfreport that might interfere with the results. Furthermore, the office employees included were randomly selected from one university. Although a number of key factors including a large sample size and the diversity of the subgroups were considered to ensure the representation of the population under study, precautions should be taken if the results of this study were to be extended to office employees from other worksites. All three health networks were affiliated to the same university (SHBUMS), and local work conditions appear to be similar. On the other hand, these three networks were in the same geographical region in Tehran city. However, the possible influences of local conditions in the different networks were not assessed in this study and this limitation should be considered in future studies. In this study, psychological tests for the participants were not done. Therefore, it is suggested to consider these evaluations in future studies to determine whether there could be some correlations with the prediction of the behavior. However, despite the mentioned limitations, this study has strong points to demonstrate the factors that could influence SE among office employees in Iran.
Findings of this study revealed that perceived barriers by the office employees may prevent them from engaging in SE while being self-efficient causes them to engage in exercising. Moreover, commitment to a plan of action as well as interpersonal influences could have an effect on performing SE. Therefore, we suggest further studies be done to confirm these findings, and consequently, proper interventions based on these predictors be designed for the office employees to engage more in SE behavior.

\section{ACKNOWLEDGMENTS}

The authors would like to thank all volunteers who participated in the study. The authors also thank research deputy of Tarbiat Modares University for its financial support for this study.

\section{SUPPLEMENTARY DATA}

Supplementary data are available at Revista de Investigación Clínica online (www.clinicalandtranslationalinvestigation.com). These data are provided by the corresponding author and published online for the benefit of the reader. The contents of supplementary data are the sole responsibility of the authors.

\section{REFERENCES}

1. Brooks JM, Iwanaga $\mathrm{K}$, Chiu $\mathrm{CY}$, et al. Relationships between self-determination theory and theory of planned behavior applied to physical activity and exercise behavior in chronic pain. Psychol Health Med. 2017;22:814-22.

2. Smith DR, Leggat PA, Speare R. Musculoskeletal disorders and psychosocial risk factors among veterinarians in Queensland, Australia. Aust Vet J. 2009;87:260-5.

3. International Association for the Study of Pain. Curriculum Outline on Pain for Physical Therapy; 2013. Available from: https:// www.iasp-pain.org/Education/CurriculumDetail. aspx?ItemNumber=2055. [Last accessed on March 7, 2019].

4. López-de-Uralde-Villanueva I, Muñoz-García D, Gil-Martínez A, et al. A systematic review and meta-analysis on the effectiveness of graded activity and graded exposure for chronic nonspecific low back pain. Pain Med. 2016;17:172-88.

5. Searle A, Spink M, Ho A, Chuter V. Exercise interventions for the treatment of chronic low back pain: a systematic review and meta-analysis of randomised controlled trials. Clin Rehabil. 2015;29:1155-67

6. World Health Organization. WHO; 2016. Available from: https:// www.who.int/news-room/fact-sheets/detail/physical-activity.

7. WHO 2015. Available from: http://www.apps.who.int/gho/ data/node.main.A893?lang=en.

8. WHO 2019. Available from: http://www.who.int/dietphysicalactivity/factsheet_inactivity/en.

9. Kisner C, Colby LA, Borstad J. Therapeutic Exercise: foundations and Techniques. Philadelphia, PA: F. A. Davis Company; 2017.

10. Caban-Martinez AJ, Lowe KA, Herrick R, et al. Construction workers working in musculoskeletal pain and engaging in lei- 
sure-time physical activity: findings from a mixed-methods pilot study. Am J Ind Med. 2014;57:819-25.

11. Mohammed M, Naji FL. Benefits of exercise training for computer-based staff: a meta-analysis. Int J Kinesiol Sports Sci. 2017; 5:16-23.

12. Ivarsson $A$, Johnson $U$, Andersen $M B$, et al. Psychosocial factors and sport injuries: meta-analyses for prediction and prevention. Sports Med. 2017;47:353-65.

13. Pender NJ, Murdaugh CL, Parsons MA. Health Promotion in Nursing Practice. Boston, MA: Pearson; 2015.

14. Szumilas M. Explaining odds ratios. J Can Acad Child Adolesc Psychiatry. 2010;19:227-9.

15. Knapp TR, Brown JK. Ten measurement commandments that often should be broken. Res Nurs Health. 1995;18:465-9.

16. Sihawong $R$, Janwantanakul $P$, Sitthipornvorakul E, Pensri $P$. Exercise therapy for office workers with nonspecific neck pain: a systematic review. J Manipulative Physiol Ther. 2011;34: 62-71.

17. Gasibat Q, Simbak NB, Aziz AA, Petridis L, Tróznai Z. Stretching exercises to prevent work-related musculoskeletal disorders: a review article. Am J Sports Sci Med. 2017;5:27-37.

18. Shariat A, Cleland JA, Danaee $M$, et al. Effects of stretching exercise training and ergonomic modifications on musculoskeletal discomforts of office workers: a randomized controlled trial. Braz J Phys Ther. 2018;22:144-53.

19. Tunwattanapong $P$, Kongkasuwan R, Kuptniratsaikul V. The effectiveness of a neck and shoulder stretching exercise program among office workers with neck pain: a randomized controlled trial. Clin Rehabil. 2016;30:64-72.

20. McEachan RR, Conner M, Taylor NJ, Lawton RJ. Prospective prediction of health-related behaviors with the theory of planned behaviors: a meta-analysis. Health Psychol Rev. 2011;5:97-144.

21. Luszczynska A, Schwarzer R. Planning and self-efficacy in the adoption and maintenance of breast self-examination: a longitudinal study on self-regulatory cognitions. Psychol Health. 2003;18:93-108.
22. Wu TY, Pender N. Determinants of physical activity among Taiwanese adolescents: an application of the health promotion model. Res Nurs Health. 2002;25:25-36.

23. Laffrey SC. Physical activity among older Mexican American women. Res Nurs Health. 2000;23:383-92.

24. Shin YH, Hur HK, Pender NJ, Jang HJ, Kim MS. Exercise self-efficacy, exercise benefits and barriers, and commitment to a plan for exercise among Korean women with osteoporosis and osteoarthritis. Int J Nurs Stud. 2006;43:3-10.

25. Pender NJ, Murdaugh CL, Parsons MA. Health Promotion in Nursing Practice. 4th ed. Upper Saddle River, New Jersey: Prentice Hall; 2002

26. Bandura A, Freeman W, Lightsey R. Self-efficacy: the exercise of control. J Cogn Psychother. 1999;13:158-66.

27. Justine M, Azizan A, Hassan V, Salleh Z, Manaf H. Barriers to participation in physical activity and exercise among middleaged and elderly individuals. Singapore Med J. 2013;54:581-6.

28. Chenary R, Noroozi A, Tavafian SS, Saeed Firoozabadi M. Effective factors on health-promoting lifestyle among Iranian chemical veterans in 2014 based on health promotion model: a path analysis. Iran Red Crescent Med J. 2016;18:e33467.

29. Alaviani M, Khosravan S, Alami A, Moshki M. The effect of a multi-strategy program on developing social behaviors based on pender's health promotion model to prevent loneliness of old women referred to gonabad urban health centers. Int J Community Based Nurs Midwifery. 2015;3:132-40.

30. Sniehotta FF, Scholz U, Schwarzer R, et al. Long-term effects of two psychological interventions on physical exercise and selfregulation following coronary rehabilitation. Int ] Behav Med. 2005; $12: 244-55$

31. Gerber M, Mallett C, Pühse U. Beyond intentional processes: the role of action and coping planning in explaining exercise behavior among adolescents. Int J Sport Exercise Psychol. 2011;9:209-26.

32. Roux L, Pratt M, Tengs TO, et al. Cost effectiveness of community-based physical activity interventions. Am J Prev Med. 2008 35:578-88 